\author{
M.Z. Youssef-Ahmed \\ P. Silver \\ L. Nimkoff \\ M. Sagy
}

\section{Continuous infusion of ketamine in mechanically ventilated children with refractory bronchospasm}

Received: 18 December 1995

Accepted: 15 February 1996
M.Z. Youssef-Ahmed · P. Silver L. Nimkoff · M. Sagy (区)

The Division of Critical Care Medicine, Schneider Children's Hospital,

New Hyde Park, NY 11042, USA

FAX: + $1(718) 4700159$

Tel.: $+1(718) 4703330$
Abstract Objective: To determine whether ketamine infusion to mechanically ventilated children with refractory bronchospasm is beneficial.

Design: Retrospective chart review. Setting: Pediatric intensive care unit (PICU) of a children's hospital. Patients: Seventeen patients, ages ranging from 5 months to 17 years (mean $6 \pm 5.7$ years), were admitted to our PICU over a 3 -year period and received ketamine infusion during a course of mechanical ventilation. The patients had acute respiratory failure associated with severe bronchospasm due to status asthmaticus $(n=11)$, bronchiolitis caused by respiratory syncytial virus $(n=4)$, and bacterial pneumonia $(n=2)$.

Interventions: All patients had been mechanically ventilated for $1-5$ days (2.2 \pm 1.5 days) and received conventional treatment to relieve bronchospasm for more than $24 \mathrm{~h}$ prior to the initiation of ketamine treatment. An intravenous bolus of ketamine of $2 \mathrm{mg} / \mathrm{kg}$, followed by continuous infusions of $20-60 \mu \mathrm{g} / \mathrm{kg}$ per minute $(32 \pm 10 \mu \mathrm{g} / \mathrm{kg}$ per minute) was administered to all patients without changing their preexisting bronchodilatory regimen. Benzodiazepines were also given intravenously to all patients during the ketamine treatment.

Measurements and main results: The $\mathrm{PaO}_{2} / \mathrm{FIO}_{2}$ ratio in all patients $(n=17)$ and the dynamic compliance in the volume-preset mechanically ventilated patients $(n=12)$ were calculated. The $\mathrm{PaO}_{2} / \mathrm{FIO}_{2}$ ratio increased significantly from $116 \pm 55$ before ketamine, to $174 \pm 82,269 \pm 151$, and $248 \pm 124$ at 1,8 , and $24 \mathrm{~h}$ respectively, after the initiation of the ketamine infusion $(p<0.0001)$. Dynamic compliance increased from $5.78 \pm 2.8$ $\mathrm{cm}^{3} / \mathrm{cmH}_{2} \mathrm{O}$ to $7.05 \pm 3.39$, $7.29 \pm 3.37$, and $8.58 \pm 3.69$, respectively $(p<0.0001) . \mathrm{PaCO}_{2}$ and peak inspiratory pressure followed a similar trend of improvement with ketamine administration. The mean duration of the ketamine infusion was $40 \pm 31 \mathrm{~h}$. One patient required glycopyrrolate $0.4 \mathrm{mg} /$ day to control excessive airway secretions and one patient required an additional dose of diazepam to control hallucinations while emerging from ketamine. All patients were successfully weaned from mechanical ventilation and discharged from the PICU.

Conclusion: Continuous infusion of ketamine to mechanically ventilated patients with refractory bronchospasm significantly improves gas exchange and dynamic compliance of the chest.

Key words Ketamine infusion Asthma - Bronchiolitis · Bronchospasm - Dynamic compliance - Oxygenation 


\section{Introduction}

Mechanical ventilation of patients with severe airway resistance and poor chest compliance, as in asthma, is often difficult $[1,2]$. Despite proper sedation, neuromuscular blockade, and aggressive bronchodilatory therapy, adequate gas exchange may not be attained in these patients and barotrauma from high mechanical inspiratory pressures may occur [3, 4]. Administration of ketamine to asthmatic patients has been shown to result in diminished bronchospasm $[5,6]$. When given to mechanically ventilated adult patients with refractory bronchospasm, a marked improvement in chest compliance has also been observed [7]. Since ketamine is a potent sedative which can be administered by continuous infusion to critically ill pediatric patients [8], its administration can provide both beneficial effects, sedation and bronchodilation. However, recognition of the potential complications of this treatment is mandatory. The emergence phenomena, excessive tracheobronchial secretions, and the cardiovascular effects may be hazardous [9], but are easily preventable or manageable by a knowledgeable and skillful care provider.

Over a 3-year period, we employed a treatment protocol utilizing continuous infusion of ketamine for mechanically ventilated children with severe refractory bronchospasm. Our goal in this retrospective study was to assess the efficacy of this treatment and its effects on dynamic compliance and gas exchange.

\section{Patients and methods}

The medical records of all patients who had received continuous ketamine infusion for severe bronchospasm during mechanical ventilation in our pediatric intensive care unit (PICU) over a 3-year period were reviewed. The clinical data collected included demographic data, diagnoses, mode and duration of mechanical ventilation, and the dose and duration of the ketamine treatment. We calculated the (partial oxygen pressure) $\mathrm{PaO}_{2} /$ (fraction of inspired oxygen) $\mathrm{FIO}_{2}$ ratio for all patients, and the dynamic compliance $(D C=T V /(P I P-P E E P)$, where TV $=$ tidal volume, $\mathrm{PIP}=$ peak inspiratory pressure, and PEEP = positive end expiratory pressure) for patients who received volume-preset mechanical ventilation, before and during the first $24 \mathrm{~h}$ of ketamine administration. Adverse effects of this treatment were also documented.

We planned to collect and analyze data only from patients in whom the bronchodilatory treatments given prior to the ketamine treatment, as well as the ventilator settings, remained unchanged during the first $24 \mathrm{~h}$ following the initiation of the ketamine infusion. In addition, patients in whom additional new bronchodilatory treatments had been introduced during the first $24 \mathrm{~h}$ of ketamine infusion were not included in the study.

The data are presented as the mean \pm SD in the text and as the mean \pm SEM in the figure. We employed one-way analysis of variance for repeated measures and the multiple comparison method of Bonferroni to identify significant changes between the pre- and post-ketamine values. We rejected the null hypothesis at $p<0.05$.

\section{Results}

Over a 3-year period, 17 patients were suitable for data collection and analysis. All patients were admitted to the PICU and received ketamine infusion for severe bronchospasm during a course of mechanical ventilation. All patients had received, prior to the initiation of ketamine infusion, continuous albuterol inhalation treatment at a dose ranging from 0.15 to $0.45 \mathrm{mg} / \mathrm{kg}$ per hour and daily intravenous methylprednisolone at $4 \mathrm{mg} / \mathrm{kg}$ divided into 4 doses. Three patients received continuous theophylline infusion at a dose ranging between 0.9 and $1.1 \mathrm{mg} / \mathrm{kg}$ per hour in addition to albuterol and methylprednisolone, and had levels within the therapeutic range $(10-20 \mathrm{mg} / \mathrm{l})$. Two other patients received continuous infusion with terbutaline at $2 \mathrm{mg} / \mathrm{kg}$ per hour in addition to albuterol and methylprednisolone.

Eleven patients had severe status asthmaticus, four had respiratory syncytial virus (RSV) bronchiolitis and two had bacterial pneumonia. The patients had been mechanically ventilated for a mean of $2.2 \pm 1.5$ days before ketamine treatment was started. All patients were paralyzed with either pancuronium or vecuronium and received only benzodiazepines for sedation in addition to ketamine (Table 1). Mechanical ventilation was guided by our permissive hypercapnia protocol, i.e., patients on volume-preset mechanical ventilation received a tidal volume that generates PIP of less than $40 \mathrm{cmH}_{2} \mathrm{O}$. Similarly, patients on pressure-preset mechanical ventilation received PIP less than $40 \mathrm{cmH}_{2} \mathrm{O}$. We abide by the protocol guidelines, as long as the resulting hypercapnia is not associated with a pH less than 7.28. Our goal is to achieve adequate oxygenation $\left(\mathrm{PaO}_{2} 65-70\right.$ torr or $\mathrm{O}_{2}$ saturation $90-95 \%$ ) with the minimal possible $\mathrm{FIO}_{2}$. Volume-preset mechanical ventilation was used in 12 patients $(\mathrm{PB}$ 7200, Puritan Bennett, Overland Park, Kan.) and the DC and the $\mathrm{PaO}_{2} / \mathrm{FIO}_{2}$ ratio were calculated. In five pa-

Table 1 Clinical data $(n=17)$

\begin{tabular}{llll}
\hline Variable & Mean & SD & Range \\
\hline $\begin{array}{l}\text { Age in years } \\
\text { Days on mechanical ventilation } \\
\text { prior to initiation of }\end{array}$ & 6 & 5.7 & $0.5-17$ \\
ketamine treatment & & 1.5 & $1-5$ \\
$\begin{array}{l}\text { Ketamine infusion } \\
\quad \text { Dose of ketamine after }\end{array}$ & 32 & 10 & $20-60$ \\
$\begin{array}{l}2 \mathrm{mg} / \mathrm{kg} \text { bolus } \\
\text { ( } \mu \mathrm{g} / \mathrm{kg} \text { per minute) }\end{array}$ & & & \\
$\begin{array}{l}\text { Duration of ketamine infusion }(\mathrm{h}) \\
\text { Additional sedation }\end{array}$ & 40 & 31 & $12-96$ \\
$\begin{array}{l}\text { Dose of midazolam } \\
(\mu \mathrm{g} / \mathrm{kg} \text { per minute) after }\end{array}$ & 3.8 & 1.4 & $2-6$ \\
$\begin{array}{l}100 \mu \mathrm{g} / \mathrm{kg} \text { bolus }(n=11) \\
\text { Daily diazepam dose }(\mathrm{mg} / \mathrm{kg}) \\
\text { divided into six dose }(n=6)\end{array}$ & 1.2 & - & - \\
\hline
\end{tabular}




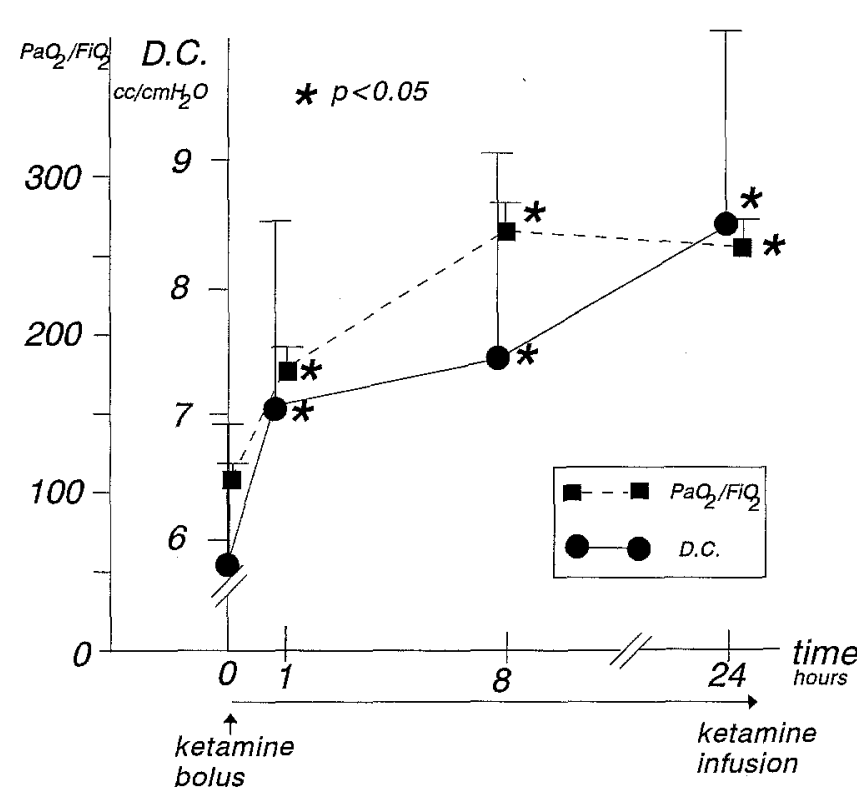

Fig. 1 The temporal changes in $\mathrm{PaO}_{2} / \mathrm{FIO}_{2}$ ratio and dynamic compliance (D.C.) following the initiation of ketamine treatment and during the first $24 \mathrm{~h}$ thereafter. Values at time 0 represent values immediately prior to (no earlier than $1 \mathrm{~h}$ ) ketamine administration. An asterisk denotes a significant change compared to time 0 $(p<0.05)$

tients, pressure-preset mechanical ventilation was used and, thus, only $\mathrm{PaO}_{2} / \mathrm{FIO}_{2}$ was calculated.

The patients' $\mathrm{DC}$ and $\mathrm{PaO}_{2} / \mathrm{FIO}_{2}$ ratio improved significantly within $1 \mathrm{~h}$ after initiation of ketamine, and the improvement persisted (Table 2, Fig. 1). The $\mathrm{PaCO}_{2}$ and PIP values followed the same trend (Table 2). Clinically, the patients with RSV and bacterial pneumonia responded to ketamine not differently from those with asthma.

Adverse effects were noted in two patients: one had excessive tracheobronchial secretions which had not been observed prior to the ketamine treatment, and another experienced hallucinations as an emergence phenomenon. These adverse effects were successfully treated, the former with glycopyrrolate $0.4 \mathrm{mg} /$ day (in four divided doses) during the ketamine infusion period, and the latter with a diazepam bolus of $0.2 \mathrm{mg} / \mathrm{kg}$. None of the patients studied demonstrated any significant change in their heart rate or blood pressure that required treatment. All patients were successfully weaned from mechanical ventilation and discharged from the PICU.

\section{Discussion}

Ketamine is a potent anesthetic which can be administered intravenously, intramuscularly, and even orally [10]. The drug induces a dissociation between the thalamoneocortical and limbic systems, providing sedation, amnesia, and analgesia [9]. It can be used safely for intraoperative anesthesia and postoperative sedation. Its metabolism occurs primarily in the liver where it is converted to norketamine by $\mathrm{N}$-methylation [11]. Children appear to metabolize ketamine more rapidly, with a half-life of $1-2 \mathrm{~h}$ [9].

Previous studies have shown that ketamine administration induces endogenous catecholamine release [12]. This explains the dose-related increase in heart rate and blood pressure in treated patients with normal myocardial function, as well as the relief of bronchospasm in asthmatic patients. Thus, the administration of ketamine to induce anesthesia and facilitate endotracheal intubation in patients with bronchospasm has become common practice [11]. When mechanical ventilation is instituted for these patients, appropriate sedation, with or without neuromuscular blockade, is also mandatory to assure that adequate gas exchange is not disrupted [13]. All of our patients were mechanically ventilated, pharmacologically paralyzed, and unresponsive to the bronchodilatory management administered prior to ketamine treatment.

To determine the degree of improvement in the patients' gas exchange resulting from ketamine administration, we elected to evaluate the trend in the $\mathrm{PaO}_{2} / \mathrm{FIO}_{2}$ ratio. This ratio is a commonly used index for oxygenation, reflecting the severity of respiratory illness [14]. We also followed the trend of the patients' $\mathrm{PaCO}_{2}$ values, as ventilation indices have not yet been commonly accepted. The $\mathrm{PaO}_{2} / \mathrm{FIO}_{2}$ ratio in our patients had been $116 \pm 55$ before ketamine treatment was started. This low ratio indicates that high, potentially toxic, concentrations of oxygen had to be administered to the patients to prevent
Table 2 Respiratory data $(D C$ dynamic compliance, $T V$ tidal volume, $P I P$ peak inspiratory pressure, $P E E P$ positive end expiratory pressure)

\begin{tabular}{lcccrl}
\hline Variable & Preketamine & \multicolumn{2}{l}{ Postketamine } & & \multirow{2}{*}{$p^{*}$} \\
\cline { 2 - 5 } & $1 \mathrm{~h}$ & $1 \mathrm{~h}$ & $8 \mathrm{~h}$ & $24 \mathrm{~h}$ & \\
\hline $\mathrm{PIP}\left(\mathrm{cmH}_{2} \mathrm{O}\right)$ & $58 \pm 17$ & $44 \pm 14$ & $38 \pm 12$ & $33 \pm 10$ & $<0.01$ \\
$\mathrm{DC}=\mathrm{TV} /(\mathrm{PIP}-\mathrm{PEEP})$ & $5.78 \pm 2.8$ & $7.05 \pm 3.39$ & $7.29 \pm 3.37$ & $8.58 \pm 3.69$ & $<0.01$ \\
$\left(\mathrm{~cm}^{3} / \mathrm{cmH}_{2} \mathrm{O}\right)(n=12)$ & $116 \pm 55$ & $174 \pm 82$ & $269 \pm 151$ & $248 \pm 124$ & $<0.01$ \\
$\mathrm{PaO}_{2} / \mathrm{FIO}_{2}$ & $59.8 \pm 9.9$ & $43.4 \pm 4.3$ & $37.9 \pm 4.2$ & $38.7 \pm 4.4$ & $<0.01$ \\
$\mathrm{PaCO}_{2}$ (torr) & &
\end{tabular}

$* p<0.01$ indicates a significant change in all postketamine values compared to baseline 
hypoxemia. The fact that within $1 \mathrm{~h}$ after ketamine administration had been initiated this ratio as well as the $\mathrm{PaCO}_{2}$ improved, suggests a cause and effect relationship between ketamine and the improved pulmonary gas exchange in our patients.

The volume-pressure relationship during mechanical ventilation is called the dynamic compliance. The DC represents the flow-dependent, or resistive pressure, changes in the respiratory system $[15,16]$. The lower the DC, the more significant the airway obstruction. In a patient with reactive airway disease, a decrease in DC would mean more severe bronchospasm, and vice versa. In all of our patients, the DC increased significantly within $1 \mathrm{~h}$ after initiation of ketamine treatment. This trend of improvement continued throughout the 24 -h study period. PIP, the main determinant of DC, followed a similar trend of improvement. That this beneficial effect on DC was, again, observed so close in time after initiation of ketamine treatment, strongly suggests that it was primarily the ketamine administration which improved the bronchospasm and thereby improved chest compliance in our patients, and not any of the other ongoing treatments.

Although the etiology of the bronchospasm in our patients was not uniform, we could not detect any clinical difference in the response to ketamine by our three groups of patients. Bronchospasm is the response of the bronchial system to offending stimuli and substances, including allergens, inflammation, infection, and foreign body aspiration. It is, therefore, not uncommon to encounter patients with RSV pneumonitis and bacterial pneumonia who develop refractory bronchospasm. The favorable response to ketamine, by all of our patients, indicates that this treatment can be used in mechanically ventilated patients with bronchospasm of various etiologies.

The clinician who elects to administer ketamine to the critically ill patient in the ICU setting has to be adept in identifying and managing its side effects. Ketamine increases salivary and bronchial gland secretion through stimulation of central cholinergic receptors [17]. Con- comitant administration of an anticholinergic drug is, therefore, recommended. This side effect was encountered in only one of our patients, and was easily controlled by daily administration of glycopyrrolate in four divided doses. Emergence phenomena or hallucinations have commonly been observed with ketamine treatment, but are effectively prevented or treated with benzodiazepines [11]. In our experience, the concomitant use of continuous infusions of midazolam or intermittent boluses of diazepam effectively reduced the incidence of this side effect, as only one of our 17 patients experienced it. Ketamine can also cause tachycardia and hypertension, possibly via an endogenous release of catecholamines [18]. This side effect was not observed in any of our patients; however, when it exists it may be deleterious. Other side effects, such as a possible increase in intracranial pressure [19] and an increase in pulmonary vascular resistance [20] may be of concern in patients with brain insults and congenital cardiac defects, respectively, but seem to be inapplicable to the patient population described in our study.

Inhalational anesthetics, halothane in particular, have been advocated in patients with refractory bronchospasm [21]. Halothane appears to be a very potent bronchodilator and is considered the inhalational anesthetic of choice for patients with asthma who have to undergo surgical procedures [22]. However, most PICUs may not be set up for this mode of therapy, and transferring critically ill patients to the operating suite may be too risky. The advantage of an intravenous anesthetic, such as ketamine, is that it can be administered in most ICU settings and does not require specific anesthesia equipment, in contrast to inhalational anesthetics.

In summary, mechanically ventilated pediatric patients with refractory bronchospasm respond to the continuous infusion of ketamine within $1 \mathrm{~h}$ after its initiation, showing a significant improvement in their dynamic compliance and oxygenation. The side effects of this treatment appear to be minimal and easily controllable.

\section{References}

1. Wood DW, Downes JJ, Lecks HI (1968) The management of respiratory failure in childhood status asthmaticus: experience with 30 episodes and evolution of a technique. Allergy 42:261-267

2. Simons FE, Pierson WE, Bierman CW (1977) Respiratory failure in childhood status asthmaticus. Am J Dis Child 131:1097-1101

3. Picado C, Montserrat JM, Roca J, Rodriguez-Rosin R, Estopa R, Xaubet A et al (1983) Mechanical ventilation in severe exacerbation of asthma: study of 26 cases with six deaths. Eur J Respir Dis 64:102-107
4. James OF, Mills RM, Allen KM (1977) Severe bronchial asthma: factors influencing intensive care management and outcome. Anaesth Intensive Care $5: 11-18$

5. Strube PJ, Hallam PL (1986) Ketamine by continuous infusion in status asthmaticus. Anaesthesia 41:1017-1019

6. Rock M, Reyes-de-la-Rocha S, L'Hommedieu CS, Truemper E (1986) Use of ketamine in asthmatic children to treat respiratory failure refractory to conventional therapy. Crit Care Med 14: $514-516$
7. Hirshman CA, Downes H, Farbood A, Bergman NA (1979) Ketamine block of bronchospasm in experimental canine asthma. Br J Anaesth 51:713-718

8. Tobias JD, Martin LD, Wetzel RC (1990) Ketamine by continuous infusion for sedation in the pediatric intensive care unit. Crit Care Med $18: 819-821$

9. Green SM, Johnson NE (1990) Ketamine sedation for pediatric procedures. Part 2: review and implications. Ann Emerg Med 19:1033-1046 
10. Tobias JD, Phipps S, Smith B, Mulhern RK (1992) Oral ketamine premedication toalleviate the distress of invasive procedures in pediatric oncology patients. Pediatrics 90:537-541

11. White PF, Way WL, Trevor AJ (1982) Ketamine - its pharmacology and therapeutic uses. Anesthesiology 56: $119-136$

12. Chernow B, Lake CR, Cruess D, Coyle $\mathrm{J}$, Hughes $\mathrm{P}$ et al (1982) Plasma, urine and CSF catecholamine concentrations during and after ketamine anesthesia. Crit Care Med 10:600-603

13. Levin N, Dillon JB (1972) Status asthmaticus and pancuronium bromide. JAMA 222:1265-1268

14. Murray JF, Matthay MA, Luce JM, Flick MR (1988) An expanded definition of the adult respiratory distress syndrome. Am Rev Respir Dis 138: $720-723$
15. Darowski MJ, Hannon VM, Hirshman CA (1989) Corticosteroids decrease airway hyperresponsiveness in the BasenjiGreyhound dog model of asthma. $\mathbf{J}$ Appl Physiol 66:1120-1126

16. Takishima $T$, Taguchi $O$, Hida W, Nogami H, Shimizu Y et al (1989) New assessment of airway responsiveness: effect of pretreatment with procaterol on allergen-induced bronchoconstriction. Chest 96:522-527

17. Vincent JP, Cavey D, Kamenka JM, Geneste P, Lazdunski M (1978) Interaction of phencyclidines with the muscarinic and opiate receptors in the central nervous system. Brain Res 152:176-182

18. Saegusa K, Furukaway Y, Ogiwara Y, Chiba S (1986) Pharmacologic analysis of ketamine induced cardiac actions in isolated blood-perfused canine atria. $\mathrm{J}$ Cardiovase Pharmacol 8:414-419
19. Gardner AE, Dannemiller FJ, Dean D (1972) Intracranial cerebrospinal fluid pressure in man during ketamine anesthesia. Anesth Analg (Cleveland) 51: $741-745$

20. Morray JP, Lynn AM, Stamm SJ, Herndon PA, Kawabori I, Stevenson JG (1984) Hemodynamic effects of ketamine in children with congenital heart disease. Anesth Analg (Cleveland) 63: $895-899$

21. Schwartz SH (1984) Treatment of status asthmaticus with halothane. JAMA 251:2688-2689

22. Fletcher SW, Flacke W, Alper MH (1968) The actions of general anesthetic agents on tracheal smooth muscle. Anesthesiology 29:517-522 